\title{
How Should We Lower Blood Pressure after Cerebral Hemorrhage? A Systematic Review and Meta-Analysis
}

\author{
Simona Lattanzi Claudia Cagnetti Leandro Provinciali Mauro Silvestrini \\ Neurological Clinic, Department of Experimental and Clinical Medicine, Marche Polytechnic University, Ancona, Italy
}

\author{
Keywords \\ Blood pressure $\cdot$ Cerebrovascular disease $\cdot$ Intracerebral \\ hemorrhage . Acute stroke
}

\begin{abstract}
Background: The optimal treatment of high blood pressure (BP) after acute intra-cerebral hemorrhage $(\mathrm{ICH})$ is controversial. Summary: The aim of the study was to evaluate the safety and efficacy of early intensive vs. conservative BP lowering treatment in patients with $\mathrm{ICH}$. Randomized controlled trials with active and control groups receiving intensive and conservative BP lowering treatments were identified. The following outcomes were assessed: 3-month mortality and combined death or major disability, 24-h hematoma growth, early neurological deterioration, occurrence of hypotension, severe hypotension, and serious treatment-emergent adverse events. Five trials were included involving 4,350 participants, 2,162 and 2,188 for intensive and conservative treatment groups, respectively. The pooled risk ratio of 3-month death or major disability was 0.96 (0.91-1.01) and the weighted mean difference in absolute hematoma growth was $-1.53(95 \% \mathrm{Cl}-2.94$ to -0.12$) \mathrm{mL}$ in the intensive compared to conservative BP-lowering. There were no differences across the treatments in the incidence rates of 3-month mortality, early neurological deterioration, hypotension, and treatment-related adverse effects other than renal events. Key Messages: The early intensive anti-hyperten-
\end{abstract}

sive treatment was overall safe and reduced the hematoma expansion in patients presenting with acute-onset spontaneous ICH and high BP levels.

(c) 2017 S. Karger AG, Basel

\section{Introduction}

The increase of blood pressure (BP) is common in patients with acute intra-cerebral hemorrhage (ICH) and relates to a multitude of factors as premorbid hypertension, response to raised intracranial pressure, stress-induced activation of neuroendocrine systems, and damage to central autonomic centers $[1,2]$. Nonetheless, the optimal antihypertensive strategy and the most desirable BP target are still controversial. The aim of our study was to evaluate the safety and efficacy of the early intensive vs. conservative BP-lowering strategy in acute spontaneous $\mathrm{ICH}$.

\section{Materials and Methods}

\section{Search Strategy}

The study was performed according to the recommendations of the Preferred Reporting Items for Systematic Reviews and MetaAnalyses statement [3]. We systematically searched (June week 4, 2016) PubMed, the Cochrane Central Register of Controlled Trials, and the US National Institutes of Health Clinical Trials Registry

\section{KARGER}

(c) 2017 S. Karger AG, Basel

E-Mail karger@karger.com

www.karger.com/ced
Simona Lattanzi

Neurological Clinic, Department of Experimental and Clinical Medicine

Marche Polytechnic University

Via Conca 71, IT-60020 Ancona (Italy)

E-Mail alfierelattanzisimona@gmail.com 
Table 1. Characteristics of included studies

\begin{tabular}{|c|c|c|c|}
\hline Reference study & Country & Participants & Intervention targets \\
\hline $\begin{array}{l}\text { Koch et al. [7], } \\
2008\end{array}$ & $\begin{array}{l}\text { USA, } \\
\text { single center }\end{array}$ & $\begin{array}{l}\text { Spontaneous ICH confirmed by CT, MAP } \geq 110 \mathrm{~mm} \mathrm{Hg} \text {, } \\
\text { enrolment within } 8 \mathrm{~h} \text { after symptom onset }\end{array}$ & $\begin{array}{l}\text { Intensive: } \\
\text { MAP < } 110 \mathrm{~mm} \mathrm{Hg} \\
\text { Conservative: } \\
\mathrm{MAP}=110-130 \mathrm{~mm} \mathrm{Hg}\end{array}$ \\
\hline $\begin{array}{l}\text { INTERACT-1 }[8] \text {, } \\
2008\end{array}$ & $\begin{array}{l}\text { International, } \\
\text { multicenter }\end{array}$ & $\begin{array}{l}\text { Spontaneous } \mathrm{ICH} \text { confirmed by } \mathrm{CT}, \mathrm{SBP}=150-220 \mathrm{~mm} \mathrm{Hg} \\
\text { ( } \geq 2 \text { readings, } \geq 2 \mathrm{~min} \text { apart), GCS }>5 \text {, enrolment within } 6 \mathrm{~h} \\
\text { after symptom onset }\end{array}$ & $\begin{array}{l}\text { Intensive: } \\
\text { SBP = } 140 \mathrm{~mm} \mathrm{Hg} \\
\text { Conservative: } \\
\text { SBP }=180 \mathrm{~mm} \mathrm{Hg}\end{array}$ \\
\hline $\begin{array}{l}\text { INTERACT-2 [9], } \\
2013\end{array}$ & $\begin{array}{l}\text { International, } \\
\text { multicenter }\end{array}$ & $\begin{array}{l}\text { Spontaneous } \mathrm{ICH} \text { confirmed by } \mathrm{CT}, \mathrm{SBP}=150-220 \mathrm{~mm} \mathrm{Hg} \\
\text { ( } \geq 2 \text { readings, } \geq 2 \text { min apart), GCS }>5 \text {, enrolment within } 6 \mathrm{~h} \\
\text { after symptom onset }\end{array}$ & $\begin{array}{l}\text { Intensive: } \\
\text { SBP < } 140 \mathrm{~mm} \mathrm{Hg} \\
\text { Conservative: } \\
\text { SBP }<180 \mathrm{~mm} \mathrm{Hg}\end{array}$ \\
\hline $\begin{array}{l}\text { ICH-ADAPT [10], } \\
2013\end{array}$ & $\begin{array}{l}\text { Canada, } \\
\text { multicenter }\end{array}$ & $\begin{array}{l}\text { Spontaneous } \mathrm{ICH} \text { confirmed by } \mathrm{CT}, \mathrm{SBP} \geq 150 \mathrm{~mm} \mathrm{Hg} \\
\text { ( } \geq 2 \text { readings, } \geq 5 \text { min apart), enrolment within } 24 \mathrm{~h} \text { after } \\
\text { symptom onset }\end{array}$ & $\begin{array}{l}\text { Intensive: } \\
\text { SBP }<150 \mathrm{~mm} \mathrm{Hg} \\
\text { Conservative: } \\
\mathrm{SBP}<180 \mathrm{~mm} \mathrm{Hg}\end{array}$ \\
\hline $\begin{array}{l}\text { ATACH-2 [11], } \\
2016\end{array}$ & $\begin{array}{l}\text { International, } \\
\text { multicenter }\end{array}$ & $\begin{array}{l}\text { Spontaneous ICH confirmed by CT, } \mathrm{SBP}>180 \mathrm{~mm} \mathrm{Hg} \\
\text { ( } \geq 2 \text { readings, } \geq 5 \text { min apart), GCS } \geq 5 \text {, enrolment within } \\
4.5 \text { h after symptom onset }\end{array}$ & $\begin{array}{l}\text { Intensive: } \\
\text { SBP = } 110-139 \mathrm{~mm} \mathrm{Hg} \\
\text { Conservative: } \\
\mathrm{SBP}=140-179 \mathrm{~mm} \mathrm{Hg}\end{array}$ \\
\hline
\end{tabular}

ATACH, antihypertensive treatment of acute cerebral hemorrhage; GCS, Glasgow Coma Scale; ICH, intracerebral hemorrhage; ICH-ADAPT, The Intracerebral Hemorrhage Acutely Decreasing Arterial Pressure Trial; INTERACT, Intensive Blood Pressure Reduction in Acute Cerebral Haemorrhage Trial; MAP, mean arterial pressure; SBP, systolic blood pressure.

(http://www.clinicaltrials.gov; online suppl. e-Appendix I; for all onlinesuppl.material,seewww.karger.com/doi/10.1159/000462986) without date or language restrictions. The reference lists of retrieved studies were reviewed to search for additional relevant reports. The protocol was not registered.

\section{Eligibility Criteria}

Studies were selected when they met the following criteria: randomized, controlled, single/double blinded, parallel trials, with active and control groups receiving intensive (aggressive) and conservative (standard) BP-lowering treatments, respectively. Participants had to meet the following criteria: any gender, any ethnicity, adult age ( $>18$ years), spontaneous, and acute onset $(<24 \mathrm{~h}) \mathrm{ICH}$.

\section{Outcome Measures}

The main outcomes were the mortality and the combined death or major disability/dependency (modified Rankin Scale [mRS] score $>2$ ) at 3 months after randomization. Secondary outcomes were the absolute and substantial hematoma growth at $24 \mathrm{~h}$ and the early neurological deterioration. All available data on the incidence of hypotension and severe hypotension within $72 \mathrm{~h}$, the occurrence of recurrent stroke (ischemic or hemorrhagic), acute coronary event, renal failure and any serious treatment-related adverse event within 3 months, and systolic BP levels at 1,6 , and $24 \mathrm{~h}$ since randomization were extracted. Since the unavailability of standardized criteria for substantial hematoma growth and early neurological deterioration, the trial-specific definitions were used (Table 2). Severe hypotension was defined symptomatic hypotension requiring active intervention.

\section{Study Selection, Data Extraction, and Assessment of the} Risk of Bias

Two review authors (S.L. and C.C.) independently assessed trials for inclusion and extracted the information. Any disagreement was resolved with a third author (L.P.). The risk of bias was assessed according to the Cochrane Collaboration's recommendations. Trial authors could be contacted for missing relevant information.

\section{Statistical Analysis}

Reported probability values were 2-sided (significance set at $<0.05)$. Heterogeneity among trials was assessed by the chisquare test and $I^{2}$ statistics for heterogeneity $[4,5]$. If the chisquare probability value was $<0.05$, heterogeneity was considered significant and interpreted according to the $I^{2}$ statistic [6]. Data across trials were pooled by the fixed-effects model; results were compared with those obtained from the random-effects model. The risk ratio (RR) and weighted mean difference (WMD), with 95\% CIs, were the measures of associations between treatment and dichotomous/continuous outcomes. Data analysis was performed using STATA/IC 13.1 statistical package (StataCorp LP, College Station, TX, USA). 
Table 2. Substantial hematoma growth and early neurological deterioration criteria

\begin{tabular}{|c|c|c|}
\hline Reference study & Substantial hematoma growth & Early neurological deterioration \\
\hline $\begin{array}{l}\text { Koch et al. [7], } \\
2008\end{array}$ & $\begin{array}{l}\text { Increase in volume of }>30 \% \text { from baseline in the } \\
\text { first } 24 \mathrm{~h}\end{array}$ & $\begin{array}{l}\text { Decrease of } \geq 2 \text { points on the NIHSS from baseline } \\
\text { to } 48 \mathrm{~h}\end{array}$ \\
\hline $\begin{array}{l}\text { INTERACT-1 [8], } \\
2008\end{array}$ & $\begin{array}{l}\text { Increase in volume of }>33 \% \text { or }>12.5 \mathrm{~mL} \text { in the } \\
\text { first } 24 \mathrm{~h}\end{array}$ & $\begin{array}{l}\text { Decrease of } \geq 2 \text { points on the GCS or an increase } \\
\text { of } \geq 4 \text { points on the NIHSS from baseline to } 72 \mathrm{~h}\end{array}$ \\
\hline $\begin{array}{l}\text { INTERACT-2 [9], } \\
2013\end{array}$ & $\begin{array}{l}\text { Increase in volume of } \geq 33 \% \text { or }>12.5 \mathrm{~mL} \text { in the } \\
\text { first } 24 \mathrm{~h}\end{array}$ & $\begin{array}{l}\text { Decrease of } \geq 2 \text { points on the GCS or an increase } \\
\text { of } \geq 4 \text { points on the NIHSS from baseline to } 24 \mathrm{~h}\end{array}$ \\
\hline $\begin{array}{l}\text { ICH-ADAPT [10], } \\
2013\end{array}$ & Increase in volume of $>6 \mathrm{~mL}$ in the first $24 \mathrm{~h}$ & $\begin{array}{l}\text { Increase of } \geq 4 \text { points on the NIHSS from baseline } \\
\text { to } 24 \mathrm{~h}\end{array}$ \\
\hline $\begin{array}{l}\text { ATACH-2 [11], } \\
2016\end{array}$ & Increase in volume of $\geq 33 \%$ in the first $24 \mathrm{~h}$ & $\begin{array}{l}\text { Decrease of } \geq 2 \text { points on the GCS or an increase } \\
\text { of } \geq 4 \text { points on the NIHSS from baseline to } 24 \mathrm{~h}\end{array}$ \\
\hline
\end{tabular}

ATACH, antihypertensive treatment of acute cerebral hemorrhage; GCS, Glasgow Coma Scale; ICH-ADAPT, The Intracerebral Hemorrhage Acutely Decreasing Arterial Pressure Trial; INTERACT, Intensive Blood Pressure Reduction in Acute Cerebral Haemorrhage Trial; NIHSS, National Institutes of Health Stroke Scale.

\section{Results}

\section{Results of the Search and Characteristics of} Included Studies

A total of 692 records were identified and 5 studies included [7-11] (Fig. 1). All studies were randomized, 2 -group, open-label, with outcomes blinded. They included 4,350 participants, 2,162 and 2,188 for the intensive and conservative treatment groups, respectively. Details of the studies and participants are given in Table 1 and online supplementary Table e-1, respectively. All trials used adequate methods of sequence generation and allocation concealment except one [7]. All studies were rated as high risk of performance and low risk of detection, attrition, and reporting bias (online suppl. Table e-2). Funnel plots and Egger statistical test did not suggest publication bias (online suppl. e-Appendix II).

\section{Study Outcomes}

No difference was found in the rates of 3-month mortality (RR [95\% CI] 0.99 [0.83-1.17]; $p=0.883$; Fig. 2) and 3 -month death or major disability (RR 0.96 [0.91-1.01]; $p=0.126$; Fig. 3 ) between the BP-lowering strategies. The WMD in absolute hematoma growth between the intensive and aggressive treatments was -1.53 ([ -2.94 to -0.12$]$; $p=0.033) \mathrm{mL}$ (Fig. $4 \mathrm{a}$ ), and the RR for substantial hematoma enlargement was $0.86(0.74-1.00) ; p=0.046$; Fig. 4b). There was no significant difference in the rates of early neurological deterioration (RR 1.03 [0.88-1.20]; $p=0.703$ ), hypotension (RR $1.56[0.61-4.00] ; p=0.352$ ), or severe hypotension (RR 0.84 [0.37-1.94]; $p=0.689$ )

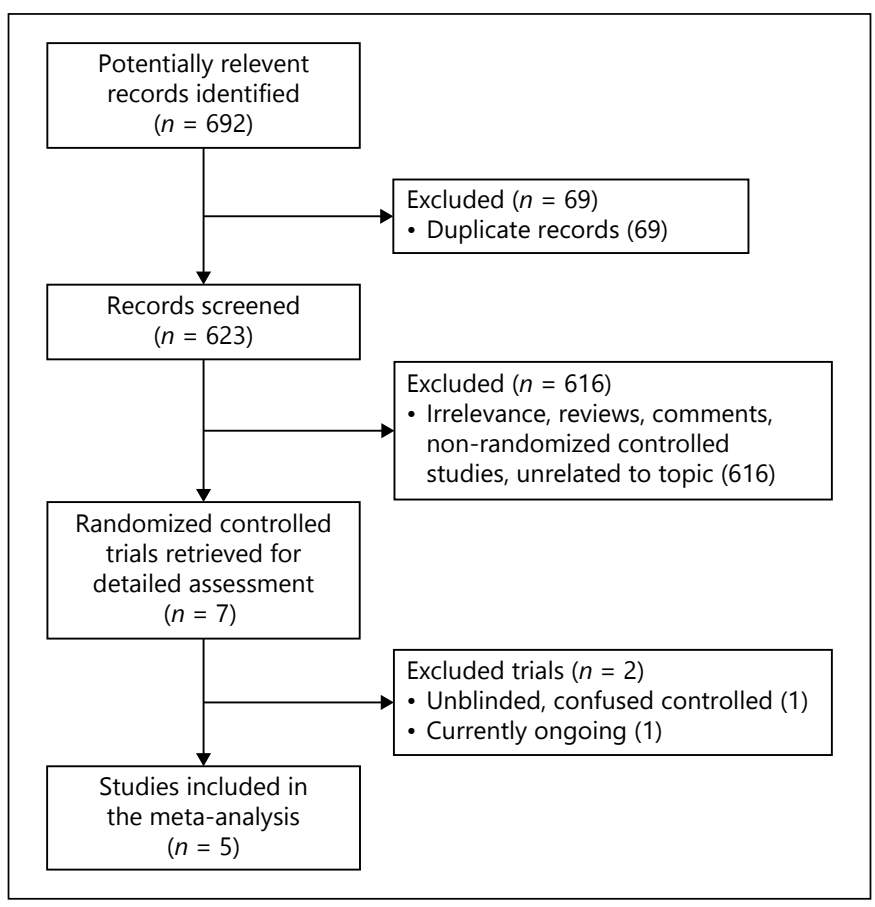

Fig. 1. Flow diagram of study identification and selection.

within $72 \mathrm{~h}$, and recurrent stroke (RR 0.95 [0.46-1.96]; $p=0.887$ ), acute coronary events (RR 1.13 [0.45-2.85]; $p=0.795)$, or serious treatment-related adverse events within 3 months (RR 1.05 [0.94-1.17]; $p=0.404$ ); a higher proportion of renal failure was found in those undergoing intensive treatment (RR 2.18 [1.08-4.41]; $p=0.031$; online suppl. Fig. e-1). Chi-square test for heterogeneity 


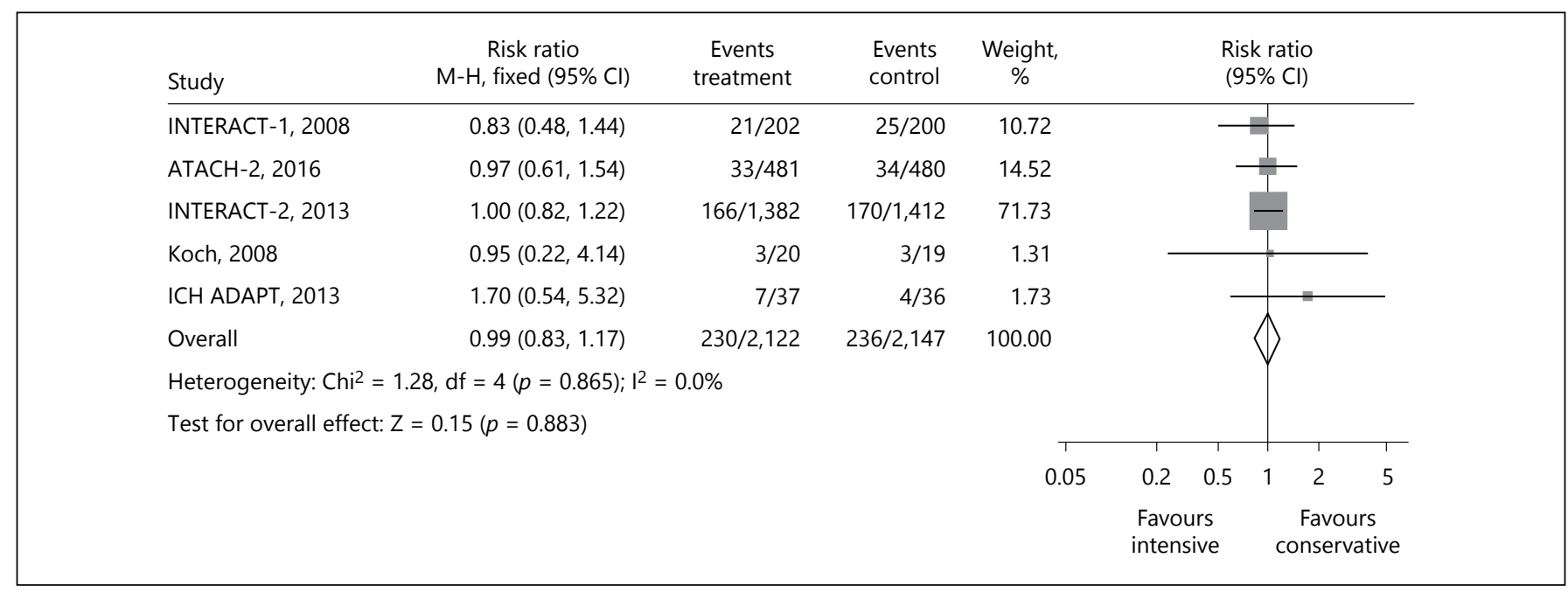

Fig. 2. Three-month mortality in intensive vs. conservative blood pressure-lowering treatment. Effect estimates are based on a fixed-effects model. Thirty-day mortality was reported in $\mathrm{ICH}$ ADAPT 2013. ATACH, antihypertensive treatment of acute cere- bral hemorrhage; df, degree of freedom; ICH ADAPT, The Intracerebral Hemorrhage Acutely Decreasing Arterial Pressure Trial; INTERACT, Intensive Blood Pressure Reduction in Acute Cerebral Hemorrhage Trial; M-H, Mantel-Haenszel.

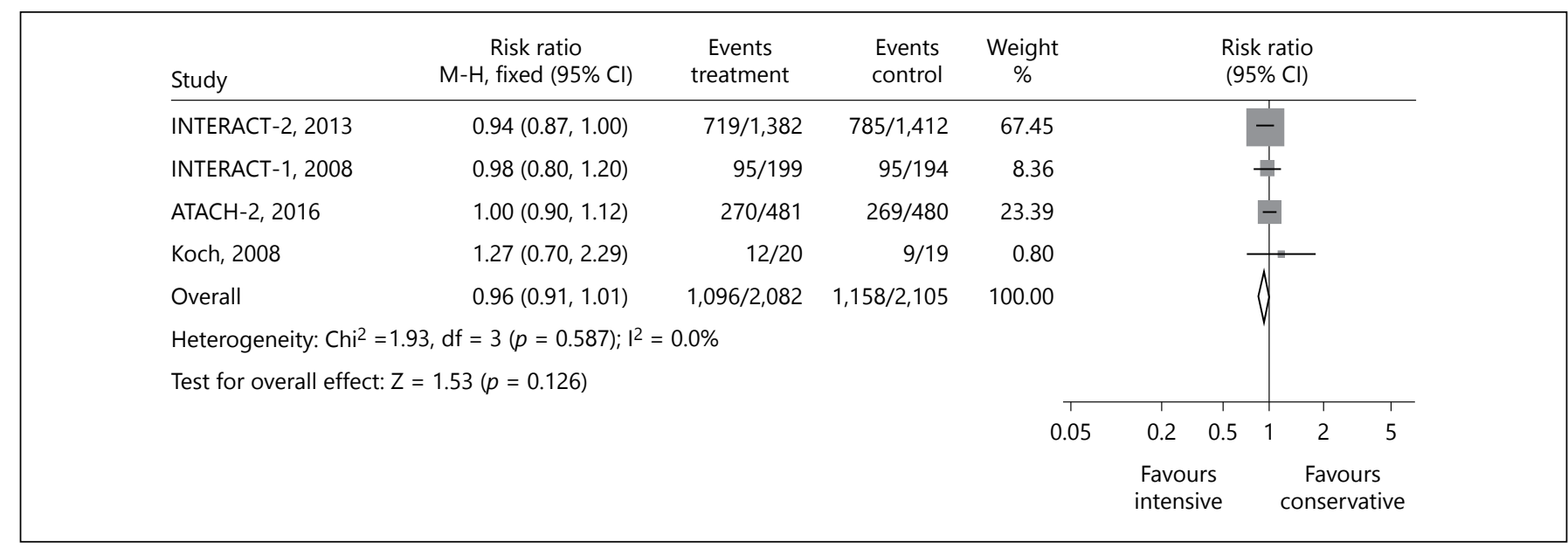

Fig. 3. Three-month death or major disability in intensive vs. conservative blood pressure-lowering treatment. Effect estimates are based on a fixed-effects model. ATACH, antihypertensive treatment of acute cerebral hemorrhage; df, degree of freedom;

indicated no significant statistical heterogeneity between trials. The WMDs in systolic BP levels between the intensive and conservative treatment arms were -13.61 ([-14.94 to -12.28$] ; p<0.001) \mathrm{mm} \mathrm{Hg},-16.73$ ([-17.98 to -15.49$] ; p<0.001) \mathrm{mm} \mathrm{Hg},-14.68$ ([-15.89 to -13.48$]$; $p<0.001) \mathrm{mm} \mathrm{Hg}$ at 1,6 , and $24 \mathrm{~h}$ after randomization (online suppl. Fig. e-2). The estimates from the randomand fixed-effects models were similar (online suppl. Table e-3). All estimates were derived from published data.
ICH ADAPT, The Intracerebral Hemorrhage Acutely Decreasing Arterial Pressure Trial; INTERACT, Intensive Blood Pressure Reduction in Acute Cerebral Hemorrhage Trial; M-H, MantelHaenszel.

\section{Discussion}

This systematic review and meta-analysis provided evidence that the early intensive BP-lowering was overall safe and attenuated the hematoma expansion in patients presenting with acute-onset $\mathrm{ICH}$ and raised $\mathrm{BP}$, but it did not significantly reduce the 3-month death or disability rate.

Major concerns with the reduction of BP since the first hours after the ICH are the safety of the anti-hypertensive 


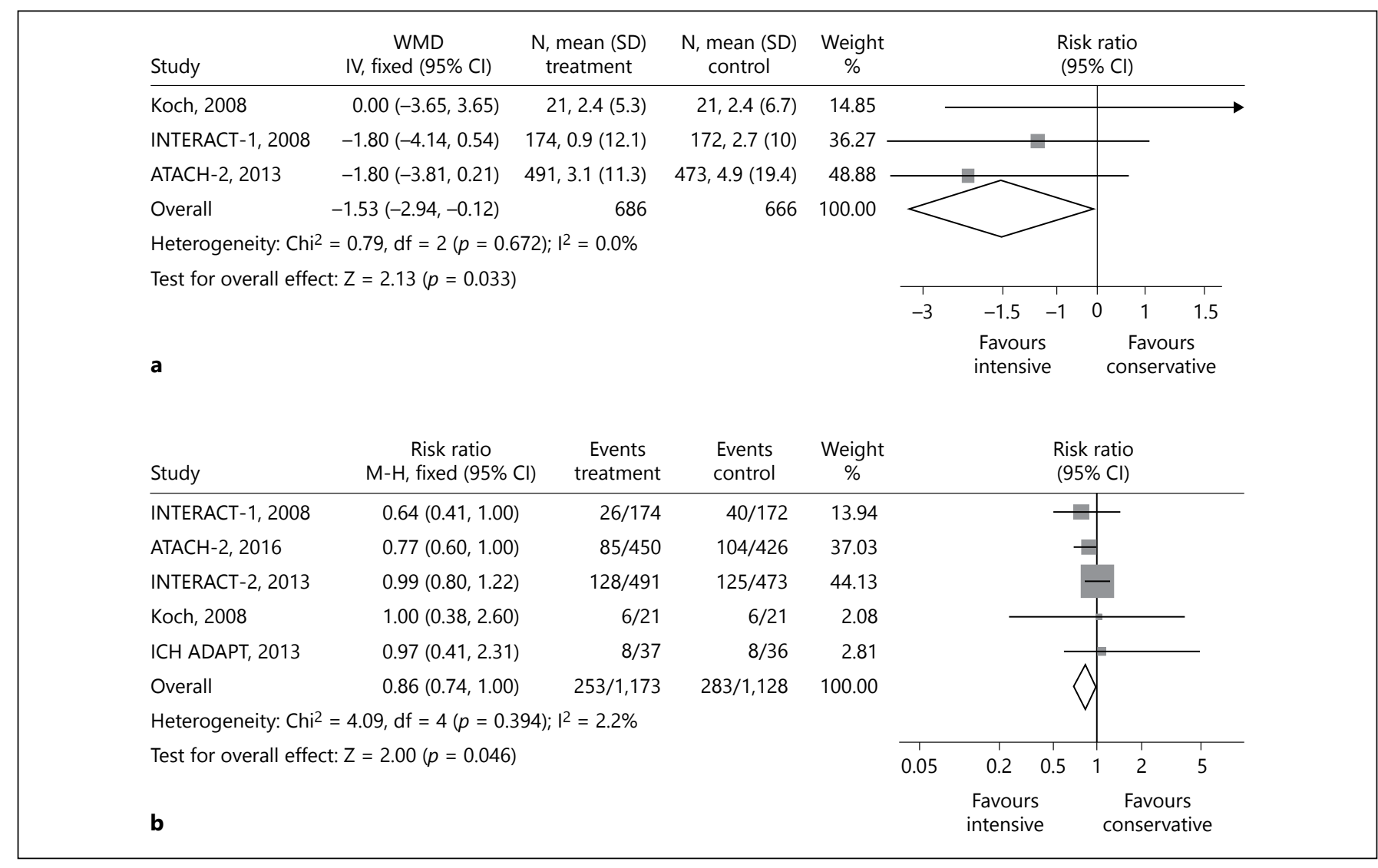

Fig. 4. Hematoma enlargement according to blood pressure-lowering therapy. a Absolute hematoma growth at $24 \mathrm{~h}$ after randomization. b Substantial hematoma growth at $24 \mathrm{~h}$ after randomization. Effect estimates are based on a fixed-effects model. ATACH, antihypertensive treatment of acute cerebral hemorrhage; df,

treatment and the risk to induce cerebral ischemia. The pooled analysis assured that the aggressive reduction of acute hypertension did not result in higher rates of death, neurological deterioration, and recurrent stroke compared to the more conservative strategy, in accordance with the upcoming evidence that early BP treatment does not significantly alter the cerebral blood flow [10].

Hematoma enlargement is favored by high admission $\mathrm{BP}$, represents a strong predictor of poor outcome, and its attenuation is thought to be one of the mechanisms by which the BP control might be beneficial [12-14]. The analysis of included trials revealed that aggressive BP-lowering reduced the hematoma growth, but failed to improve clinical outcome. The lack of clear-cut improvement of the 3-month status may have found many explanations. The difference in the rate of poor outcome observed across the treatment arms was smaller than that expected on the basis of the entity of hematoma reduc-

How Should We Lower BP after Cerebral Hemorrhage? degree of freedom; ICH ADAPT, The Intracerebral Hemorrhage Acutely Decreasing Arterial Pressure Trial; INTERACT, Intensive Blood Pressure Reduction in Acute Cerebral Hemorrhage Trial; IV, inverse variance; $\mathrm{M}-\mathrm{H}$, Mantel-Haenszel; WMD, weighted mean difference.

tion [15]. The high proportion of patients with mild to moderate hematoma volume may have increased the likelihood of good outcome irrespective of treatment, masking the real effectiveness of intervention due to ceiling effect, and reduced the risk of hematoma enlargement itself. The mean onset-to-treatment time exceeded the $3 \mathrm{~h}$ in all trials, and two-thirds of the participants randomized to the intensive arm did not reach the goal within $1 \mathrm{~h}$. The delay in starting treatment and the failure in achieving BP targets in a timely fashion may have diluted the effectiveness of the intervention by reducing the actual proportion of patients treated within the time window in which BP lowering is expected to exert greater benefit [16]. The conventional dichotomous outcome analysis according to pre-specified mRS threshold may be underpowered to detect smaller effects. Accordingly, ordinal shift approach revealed a significantly better functional recovery over 7, 28, and 90 days among pa- 
tients assigned to aggressive treatment in the INTERACT trials [17]. The relationship between $\mathrm{BP}$ and outcome may be more complex than simply linear; the clinical benefit may not increase in parallel to the degree of BP lowering, or it may be attributable to mechanisms other than absolute $\mathrm{BP}$ reduction. BP variability is strongly predictive, and the benefit of early treatment is enhanced by smooth and consistent BP control [18-21]. Current analysis could not investigate the influence of BP fluctuations, but the blunting of variations may have influenced the clinical outcome regardless of the degree of absolute BP fall.

Different caveats needed to be considered while interpreting current analysis. Few trials met the eligibility criteria and 2 accounted for near the $90 \%$ of the overall population. Patients with large $\mathrm{ICH}$, early planned decompressive neurosurgery, or BP beyond $220 \mathrm{~mm} \mathrm{Hg}$ were excluded. Accordingly, the results cannot be generalized to patients with more severe $\mathrm{ICH}$, raise in intracranial pressure, or impairment of cerebral perfusion. The mean age was 65 years, and the effects of altering BP in older people need further evidence. Anti-hypertensive agents influence tolerability, timing, and degree of BP reduction [22]: the assessment of drug-class effects was beyond our aim, but the pharmacological heterogeneity left uncertainty about the most desirable protocol. The BP targets did not exactly overlap across the trials and were set up according to the recommendations in place at the time of the investigations. The higher rate of renal failure in the intensive arm was driven by the trial with the lowest BP target, selectively achieved through nicardipine, and deserves further attention.

Our meta-analysis provided the best currently available and comprehensive evidence for the safety and efficacy of early BP-lowering after acute $\mathrm{ICH}$, and updated previous reviews and current guidelines [23-26]. The intensive treatment did not have detrimental ef- fects on the neurological status nor serious adverse events, and favorably altered the natural history of hematoma growth. Conversely, it did not convincingly demonstrate any clinical benefit in the overall population. Taking the results together, the acute reduction of systolic BP to $140 \mathrm{~mm} \mathrm{Hg}$ would be reasonable in ICH patients presenting with BP levels between 150 and $220 \mathrm{~mm} \mathrm{Hg}$ and without contraindications to BP lowering. A number of issues, including the optimal timing of BP targeting and the patient- and hematoma-features, which could influence the BP goal, should deserve further evidence. The enrollment of patients within $3 \mathrm{~h}$ from symptom onset should require the challenging, although feasible [27], intervention in the pre-hospital setting. Since patients with better recovery were those who achieved the target within the first hours, sustained it throughout the days and avoided peaks [9], BP control should be extended up to the first week after ICH. Subgroup analysis according to hematoma expansion predictors, as the CT angiographic spot sign, and surrogate end points, as the peri-hematoma edema or intra-ventricular hemorrhage extension, might help to identify the patients who are most likely to benefit and understand underlying physiopathology. Finally, ordinal analysis of outcome with proportional odds logistic regression or sliding dichotomy approach should be preferred to increase statistical power. The Intracerebral Hemorrhage Acutely Decreasing Arterial Pressure Trial II (ClinicalTrials.gov number, NCT02281838) is actively recruiting participants within $6 \mathrm{~h}$ after ICH and it is expected to provide insights into the effects of intensive BP by exploring the lesion burden on the diffusion-weighted imaging.

\section{Disclosure Statement}

The authors declare that they have no conflict of interest.

\section{References}

1 Qureshi AI, Tuhrim S, Broderick JP, et al: Spontaneous intracerebral hemorrhage. N Engl J Med 2001;344:1450-1460.

2 Qureshi AI, Ezzeddine MA, Nasar A, et al: Prevalence of elevated blood pressure in 563,704 adult patients with stroke presenting to the ED in the United States. Am J Emerg Med 2007;25:32-38.

3 Moher D, Liberati A, Tetzlaff J, et al; PRISMA Group: Preferred reporting items for system- atic reviews and meta-analyses: the PRISMA statement. PLoS Med 2009;6:e1000097.

4 Higgins JP, Thompson SG, Deeks JJ, et al: Measuring inconsistency in meta-analyses. BMJ 2003;327:557-560.

5 Higgins JP, Thompson SG: Quantifying heterogeneity in a meta-analysis. Stat Med 2002; 21:1539-1558.

6 Deeks JJ, Higgins JPT, Altman DG: Chapter 9: analysing data and undertaking meta-anal- yses; in Higgins JPT, Green S (eds): Cochrane Handbook for Systematic Reviews of Interventions Version 5.1.0 (Updated March 2011). The Cochrane Collaboration, 2011. http://handbook.cochrane.org/ (accessed June 2016).

7 Koch S, Romano JG, Forteza AM, et al: Rapid blood pressure reduction in acute intracerebral hemorrhage: feasibility and safety. Neurocrit Care 2008;8:316-321. 
8 Anderson CS, Huang Y, Wang JG, et al; INTERACT Investigators: Intensive blood pressure reduction in acute cerebral haemorrhage trial (INTERACT): a randomised pilot trial. Lancet Neurol 2008;7:391-399.

9 Anderson CS, Heeley E, Huang Y, et al; INTERACT2 Investigators: Rapid blood pressure lowering in patients with acute intracerebral hemorrhage. N Engl J Med 2013;368: 2355-2365.

10 Butcher KS, Jeerakathil T, Hill M, et al; ICH ADAPT Investigators: The intracerebral hemorrhage acutely decreasing arterial pressure trial. Stroke 2013;44:620-626.

11 Qureshi AI, Palesch YY, Barsan WG, et al; ATACH-2 Trial Investigators and the Neurological Emergency Treatment Trials Network: Intensive blood-pressure lowering in patients with acute cerebral hemorrhage. N Engl J Med 2016;375:1033-1043.

12 Rodriguez-Luna $D$, Piñeiro S, Rubiera $M$, et al: Impact of blood pressure changes and course on hematoma growth in acute intracerebral hemorrhage. Eur J Neurol 2013;20: 1277-1283.

13 Dandapani BK, Suzuki S, Kelley RE, et al: Relation between blood pressure and outcome in intracerebral hemorrhage. Stroke 1995;26: 21-24.

14 Brouwers HB, Greenberg SM: Hematoma expansion following acute intracerebral hemorrhage. Cerebrovasc Dis 2013;35:195-201.

15 Davis S, Broderick J, Hennerici M, et al; Recombinant Activated Factor VII Intracerebral Hemorrhage Trial Investigators: Hematoma growth is a determinant of mortality and poor outcome after intracerebral hemorrhage. Neurology 2006;66:1175-1181.

16 Anderson CS, Huang Y, Arima $\mathrm{H}$, et al; INTERACT Investigators: Effects of early intensive blood pressure-lowering treatment on the growth of hematoma and perihematomal edema in acute intracerebral hemorrhage: the Intensive Blood Pressure Reduction in Acute Cerebral Haemorrhage Trial (INTERACT). Stroke 2010;41:307-312.

17 Wang X, Arima H, Al-Shahi Salman R, et al: Rapid blood pressure lowering according to recovery at different time intervals after acute intracerebral hemorrhage: pooled analysis of the INTERACT studies. Cerebrovasc Dis 2015;39:242-248.

18 Manning L, Hirakawa $\mathrm{Y}$, Arima $\mathrm{H}$, et al; INTERACT2 Investigators: Blood pressure variability and outcome after acute intracerebral haemorrhage: a post-hoc analysis of INTERACT2, a randomised controlled trial. Lancet Neurol 2014;13:364-373.

19 Lattanzi S, Cagnetti C, Provinciali L, et al: Blood pressure variability and clinical outcome in patients with acute intracerebral hemorrhage. J Stroke Cerebrovasc Dis 2015; 24:1493-1499.

20 Lattanzi S, Silvestrini M: Optimal achieved blood pressure in acute intracerebral hemorrhage: INTERACT2. Neurology 2015;85: 557-558.

21 Lattanzi S, Silvestrini M: Blood pressure in acute intra-cerebral hemorrhage. Ann Transl Med 2016;4:320.

22 Webb AJ, Rothwell PM: Effect of dose and combination of antihypertensives on interindividual blood pressure variability: a systematic review. Stroke 2011;42:28602865.

23 Tsivgoulis G, Katsanos AH, Butcher KS, et al: Intensive blood pressure reduction in acute intracerebral hemorrhage: a meta-analysis. Neurology 2014;83:1523-1529.

24 Ma J, Li H, Liu Y, You C, Huang S, Ma L: Effects of intensive blood pressure lowering on intracerebral hemorrhage outcomes: a metaanalysis of randomized controlled trials. Turk Neurosurg 2015;25:544-551.

25 Pan C, Hu Y, Liu N, Zhang P, Zhang YP, Aimaiti M, Deng H, Tang YX, Xu F, Zhu SQ, Tang ZP: Aggressive blood pressure lowing therapy in patients with acute intracerebral hemorrhage is safe: a systematic review and meta-analysis. Chin Med J (Engl) 2015;128: 2524-2529.

26 Hemphill JC 3rd, Greenberg SM, Anderson CS, et al; American Heart Association Stroke Council; Council on Cardiovascular and Stroke Nursing; Council on Clinical Cardiology: Guidelines for the management of spontaneous intracerebral hemorrhage: a guideline for healthcare professionals from the American Heart Association/American Stroke Association. Stroke 2015;46:20322060.

27 Ankolekar S, Fuller M, Cross I, et al: Feasibility of an ambulance-based stroke trial, and safety of glyceryl trinitrate in ultra-acute stroke: the rapid intervention with glyceryl trinitrate in hypertensive stroke trial (RIGHT, ISRCTN66434824). Stroke 2013;44:31203128. 